\title{
The Analysis about Public Sports Infrastructures Development and Financing Methods in Gansu Province*
}

\author{
Fan JIANG ${ }^{1}$, Ying $\mathrm{LUO}^{2}$, Xiaotang $\mathrm{LI}^{3}$, Zhiliang ZENG ${ }^{4}$ \\ ${ }^{1)}$ Department of Sports Lanzhou University of Technology, LanZhou, GanSu, PRC \\ ${ }^{2)}$ Department of Sports Lanzhou University of Technology, LanZhou, GanSu, PRC \\ ${ }^{3)}$ Department of Sports Lanzhou University of Technology, LanZhou, GanSu, PRC \\ 4) Department of Sports Lanzhou University of Technology, LanZhou, GanSu, PRC
}

\begin{abstract}
This paper takes the method of historical documents and mathematical statistics as main research methods. After analyzed the current situation about the public sports infrastructures development and financing methods, main reasons hinder the development of public sports infrastructures in Gansu province due to lack of diversified financing methods and funds; the regulations about public sports infrastructures investing, construction, operation, and supervise are deficient; the financin g capacity at different cities and counties are quite different. In order solve these problems, we recommend take various financing methods, establish a sound system for investment, construction, operation, and supervise, and increase efficiency of financial resourc es usage.
\end{abstract}

Keywords - sports infrasture, construction, financing

\section{甘肃省体育基础设施建设与融资对策分析}

$$
\begin{aligned}
& \text { 姜帆 }{ }^{1} \text { 罗英 }^{2} \text { 李小唐 }^{3} \text { 曾治良 }^{4} \\
& \text { 1) 兰州理工大学体育部, 兰州, 甘肃, 中国 } \\
& \text { 2) 兰州理工大学体育部, 兰州, 甘肃, 中国 } \\
& \text { 3) 兰州理工大学体育部, 兰州, 甘肃, 中国 } \\
& \text { 4) 兰州理工大学体育部, 兰州, 甘肃, 中国 }
\end{aligned}
$$

摘 要 采用文献资料法与数理统计法对甘肃省体育基础设施建设及融资现状进行分析, 发现阻碍甘肃省体育基础基础建设的主 要因素是筹资渠道单一、资金不足; 体育公共基础设施投资、建设及开放运营监管机制不完善; 各市州财政能力相差较大。针对 此现状，建议采用多元化的筹资模式；建立完善的投资运营机制、体系；提高财政资金的使用效率。

关键词 体育基础设施，建设，融资

\section{1. 引言}

党的十八大报告中，首次提出了 “基本公共服务均等 化”要求，我国现在“必须加快建设政府指导、覆盖全民、 可持续的公共服务体系”, 确保人民共享发展成果。体育基 础设施是构建体育公共服务体系的基本要素, 从宏观方面 看, 是衡量体育事业发展程度的标志; 从微观方面看, 是 对全国 13 亿人民体质与健康的考量。近年来, 甘肃省政府、 省体育局为加快体育事业的发展, 积极探寻适合甘肃省省
情的体育事业发展路子。“雪碳工程”、“民康工程”、“体育 四进社区”、“体育三下乡”、“篮球进乡镇” 等在全省不断 开展实施, 集中有限的财力, 使得体育基础设施建设能够 快速发展，但基于甘肃省经济、人口、体育投资模式等因 素, 体育基础设施建设仍很落后。

*甘肃省高等学校科研项目 


\section{2. 甘肃省体育公共基础设施概况}

\section{1 供给现状}

体育基础设施是体育事业发展的重要物质基础, 是发 展竞技体育和群众体育的重要阵地, 也是推进体育产业、
体育文化建设的重要物质条件。体育公共基础设施的建设 与开放运用对人民参加体育锻炼的积极性、锻炼成本的降 低以及广大群众的生活环境的改善、身体素质的提高起着 重要作用。然而最新调查结果显示, 甘肃省人均体育场地 面积仅为 0.76 平方米, 远远落后于人均 1.3 平方米的水平 [1]。

表 1 甘肃省各市体育场地统计

\begin{tabular}{|c|c|c|c|c|c|}
\hline 市州名称 & 场地总数 & 占全省比例 & 场地总面积 (平方米) & 人均面积 (平方米) & 万人拥有场地数 (个) \\
\hline 兰州市 & 2259 & $12.9 \%$ & 341058 & 1.0 & 10.6 \\
\hline 嘉峪关市 & 216 & $1.2 \%$ & 433402 & 2.1 & 16.7 \\
\hline 金昌市 & 778 & $4.4 \%$ & 1546808 & 3.3 & 6.4 \\
\hline 白银市 & 1111 & $6.3 \%$ & 1482352 & 0.85 & 4.8 \\
\hline 天水市 & 1634 & $9.3 \%$ & 1554866 & 0.46 & 7.6 \\
\hline 武威市 & 1434 & $8.2 \%$ & 1989400 & 1.0 & 12.9 \\
\hline 张掖市 & 1636 & $9.3 \%$ & 1747370 & 1.4 & 15.2 \\
\hline 平凉市 & 1371 & $7.8 \%$ & 1351021 & 0.62 & 7.7 \\
\hline 酒泉市 & 1496 & $8.5 \%$ & 1735164 & 1.7 & 5.6 \\
\hline 庆阳市 & 1923 & $10.9 \%$ & 2000940 & 0.79 & 2.3 \\
\hline 定西市 & 1656 & $9.4 \%$ & 1204826 & 0.41 & 5.7 \\
\hline 陇南市 & 619 & $3.9 \%$ & 476597 & 0.18 & 4.8 \\
\hline 临夏州 & 1107 & $6.2 \%$ & 720332 & 0.37 & 0.57 \\
\hline 甘南州 & 329 & $1.9 \%$ & 389399 & & \\
\hline
\end{tabular}

资料来源：甘肃省统计年鉴

由上表可以看出, 甘肃省 14 个市县体育场地总数相差 较大, 人均体育场地面积均较少, 在 14 个市县中拥有的场 地总数较少是嘉峪关市及甘南州, 但嘉峪关与甘南州的场 地总面积较大, 人均面积大, 尤其是嘉峪关。在白银市、 天水市、平凉市、庆阳市、定西市、陇南市、临夏州、甘 南州人均体育场地面积低于 1 平方米, 尤其是陇南市人均 面积为 0.18 平方米, 人均场地面积太低。这严重影响了各 市县的体育发展。从各市县体育场地数量可以推出体育设 施供给肯定不足。

\section{2 现有的农村体育基础设施建设的筹资方式}

在具有中国特色的社会主义市场经济的背景下，我国 的体育基础设施建设资金来源方式主要有政府财政拨款、 社会企业投资、提取体育彩票公益金等。筹资方式比较单 一, 比例失衡。如图一所示, 是我国 2011 年城市公共设施 投资各类资金来源的比重。

甘肃省地处内陆, 环境闭塞, 经济欠发达, 这就导致 了经济市场的不活跃，金融工具运用的贫乏。体育公共基 础设施建设的筹资方式只能依靠国内贷款、地方财政、自 筹等途径。但是在经济欠发达的甘肃, 政府财政也有限。 所以单一的融资方式必定会导致体育基础设施的市场供给 失灵。 


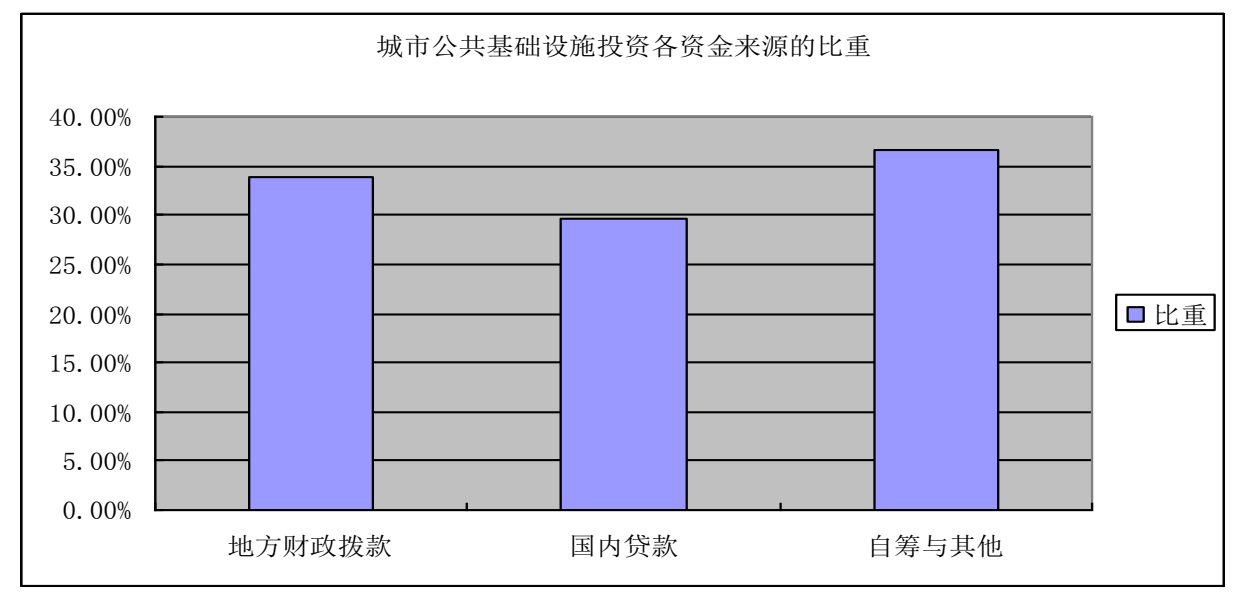

图一 城市公共基础设施投资各资金来源的比重

资料来源: 《中国城乡建设统计年鉴2011》

\section{3. 影响甘肃省体育公共基础设施建设的因素}

\section{1 体育公共基础设施融资机制单一}

我国体育基础设施建设主要依靠政府, 主要资金来源 有政府直接的财政投资、国债、体育发展基金、地方建设 债券、政策性金融机构、政府外债。如此单一的融资模式, 必然会阻碍体育基础设施的建设。祁永忠和橸彦认为, 地 方政府融资平台存在的问题包括设立不规范、管理制度落 后、信息披露不完全、融资杜杆率偏高、融资渠道单一、 现金流覆盖偏低等 $[1]$ 。再者甘肃省是西部地区, 经济不发 达，各级政府财政收入有限，可支出的财政资金不充裕， 划拨给体育方面的就更有限了。2014 年甘肃省初步汇总的 全省公共财政收入预算为 660 亿元, 全年公共财政支出预 计达到 2500 亿元以上。省级收入预算为 196.2 亿元, 加上 预计中央财力性补助和市县上缴收入、动用地方政府债券 后，支出预算安排为 396.8 亿元，其中: 基本支出 116.3 亿元, 项目支出 280.5 亿元。“十大惠民工程”, 省级共安 排资金 78 亿元 [2]。预算资金很可观, 但是平均到甘肃省 14 个市州, 在平均到每区每县、每人就所剩无几了。

3.2 体育公共基础设施投资、建设及开放运营监管机制不完 善

体育基础设施的建设最终受益者是广大人民群众, 因 此最大限度的满足人民的需求是我们奋斗的目标。这也是 实现基本公共服务均等化的要求与目标 [3]。甘肃省体育公 共基础设施建设运营监管机制还不完善, 体育公共服务部 门事权、财权不对称; 体育行政部门体育发展策略存在缺
陷，不完善的服务体系体系与不规范的决策机制。地方政 府部门的决策者利用自己现有的职位与拥有的权力去做出 体育公共产品供给决策而满足自己政绩和利益的需要, 因 此决策者往往将有限的财力用于一些见效快, 易出政绩的 短期体育基础设施的供给与建设。致使体育公共基础设施 的供给严重不足, 造成供需结构失衡, 供不应求。

\section{3 甘肃省各市州财政能力相差较大，资金投入不均衡}

甘肃省共有 14 个市州县, 经济发展程度有很大差异, 导致财政能力相差很大直接影响了各级政府对当地的体育 公共基础设施的财政资金支持力度。政府的财政拨款是现 阶段体育公共基础设施建设的重要资金来源。而现阶段甘 肃省的体育公共基础设施需要改进与新建的还有很多, 尤 其是老少边穷地区, 需要的资金数量相当可观。各市州政 府的资金支持力度差异很大，各市居民可享受的服务质量 可就存在较大的差距。

\section{4. 对策及建议}

4.1 采取多元化融资方式, 制定优惠政策, 吸引社会融资

美国政治经济学家奥斯特罗姆夫妇认为要突破政府作 为公共领域垄断者的独占中心治理模式，建立政府、市场 和社会三维框架下的多中心治理模式 [4]。甘肃省应该紧抓 西部大开发战略、丝绸之路经济带建设等发展机遇, 充分 利用国家对甘肃省的各项扶持政策，并且用足、用活、用 好这些政策，努力争取中央政策和资金支持，进一步提高 财政保障能力。政府能够允许通过金融机构中介发行专门 
用于体育基础设施建设的地方债券; 利用体育博彩业的成 功经验, 发行 “体育基础设施建设彩票”; 利用市场竞争机 制, 吸纳社会投资, 提高体育基础设施投资效率; 利用城 市维护建设税这一税收科目啦, 扩大税基, 提高税率来为 体育基础设施增资。这样既可以有效地运用财政资金, 又 可以活跃市场，也可以为民间资本提供了一个较好的投资 渠道, 真正建立政府、市场和社会三维框架下的多元融资 模式。

\section{2 建立完善的投资运营机制、体系}

建立完善的投资运营机制、体系, 达到供需均衡, 满 足居民的需求, 是我们目前的奋斗目标。体育基础设施建 设的资金主要来源于财政拨款, 社会支持很少, 单一的模 式需要完善。政府应该向市场放权, 更大程度的发挥市场 作用, 引入市场化的融资方式进行有效补充。利用各种金 融工具从金融市场上开拓体育基础设施建设融资新渠道, 如发行体育基础设施建设特种国债、企业债券等; 开发体 育基础设施广告经营权、冠名权及土地资源开发权等。政 府向社会放权, 在公共服务与管理领域把部分职能以授权、 委托等方式转移给相关社会组织、企业承担, 提高效率, 降低成本。体育基础设施经营权转让给社会组织或投资者, 委托经营管理, 政府只需履行经济调节、市场监管、公共 服务等职能。

4.3 集中有限的财力, 有效的利用政府补贴, 降低各市区差 异

天下之治乱, 不在一姓之兴亡, 而在万民之忧乐。提 供完备的公共服务便是安民生、稳民心之第一要义。为了 实现甘肃省体育公共基础设施达到基本公共服务均等要 求, 甘肃省政府应该努力创造良好的环境和基础。优化转
移支付制度，对专项转移支付项目进行优化整合，增加一 般性转移支付比重, 优化转移支付项目, 严格转移支付标 准和程序，财政投入向贫困地区倾斜，向基本公共服务倾 斜, 进而提高各市政府的公共服务能力。财政收入取之于 民，用之于民。所以必须盘活财政存量，用好财政增量， 建立结转结余资金定期清理机制，提高财政管理效能，调 整优化支出结构, 保证公共基础设施建设, 充分发挥财政 资金的杜杆作用。

\section{5. 结论}

甘肃省体育公共基础设施建设方面存在很多困境, 体 育公共基础设施融资机制单一、体育公共基础设施投资建 设及运营监管机制不完善、各市州财政能力相差较大，资 金投入不均衡。面对这些困境，甘肃省可以采取多元化融 资方式，制定优惠政策，吸引社会融资；建立完善的投资 运营机制、体系; 集中有限的财力, 有效的利用政府补贴, 降低各市区差异。通过这些方法, 甘肃省体育公共基础设 施必能很好的服务于公民。

\section{参考文献(References)}

[1] Qi Yongzhong, Luan yan. The Risk and Treatment of Local Government Financing Platform. Theoretical Exploration, 2012, (2): $86-90$

[2] The Report on the Provincial Budget Draft in 2014.

[3] Huan Changdian,Xiao Linpeng.The Original Exploration on Public Sports Service Equalization. Sports Culture Guide, 2008, $2: 14-17$

[4] Michael Mcginnis.Polycentricity and Local Public Economies, Translation by Mao, Shoulong. ShangHai: Shanghai Joint Publishing Press, 2000:59—68. 